\section{Symptom burden of sleep-disordered breathing in mild-to-moderate congestive heart failure patients}

\author{
P.C. Hastings*, , A. Vazir*,\#, , D.M. O’Driscoll*,", M.J. Morrell", and A.K. Simonds*,
}

ABSTRACT: The symptom burden resulting from sleep-disordered breathing (SDB) in patients with mild-to-moderate congestive heart failure (CHF) is unclear. The current authors monitored 24-h activity levels and compared subjective and objective measures of daytime sleepiness in 39 CHF patients, New York Heart Association class 2-3, on optimal medication. A total of 22 patients were classified as SDB (apnoea/hypopnoea index (AHI) median (range) 22.3 (16.6-100) events $\left.\cdot h^{-1}\right)$, and 17 as no SDB (NoSDB; AHI $3.7(0-12.3)$ events $\left.\cdot h^{-1}\right)$. SDB was defined as AHI $\geqslant 15$ events $\cdot h^{-1}$. Patients were assessed by $24-h$ activity monitoring (actigraphy) for a period of up to 14 days, a single objective sleepiness test (Oxford Sleep Resistance test) and Epworth Sleepiness Scale.

The duration of daytime activity was significantly shorter in the SDB group compared with the NoSDB group. The SDB group also had increased time in bed and poorer sleep quality, as shown by the fragmentation index. Objectively the SDB group when compared with the NoSDB group were significantly sleepier, subjectively the groups did not differ. The amount of napping was similar for both groups.

Despite the lack of subjective symptoms of daytime sleepiness, congestive heart failure patients with sleep-disordered breathing were objectively sleepier during the day and had reduced daytime activity with longer periods in bed and poorer sleep quality when compared with those without sleep-disordered breathing.

KEYWORDS: Actigraphy, activity, daytime sleepiness, heart failure, napping

E xcessive daytime sleepiness is a key feature of obstructive sleep apnoea (OSA). Repetitive arousals from sleep occur at the termination of an apnoea and result in sleep fragmentation with symptoms of sleepiness. This can lead to a reduced quality of life, occupational problems and an increased risk of road traffic accidents [1]. Treatment of OSA with continuous positive airway pressure (CPAP) therapy is strongly linked to the relief of excessive daytime sleepiness $[2,3]$.

Sleep-disordered breathing (SDB) is common in patients with severe congestive heart failure (CHF) $[4,5]$. However, unlike patients with OSA, CHF patients with SDB frequently do not report symptoms of excessive daytime sleepiness, despite having a high apnoea/hypopnoea index (AHI) [6]. Nevertheless, CHF patients with SDB are objectively sleepy during the day, regardless of not reporting subjective symptoms [6]. Further objective measures of daytime sleepiness may help with assessing the symptom profile of these patients.
Actigraphy is a tool which has been widely used in sleep research to monitor activity over 24-h periods $[7,8]$ in a variety of patient groups $[9,10]$. Actigraphy has been shown to correlate well with polysomnography $[7,11]$. It can be used to define wake epochs during nocturnal sleep, and has also been used to monitor daytime napping in healthy populations [8]. Daytime napping and 24-h activity levels have not previously been documented in CHF patients with or without SDB. The purpose of the present study was to monitor 24-h activity levels in CHF patients with SDB over a 2-week period using actigraphy. More specifically, the current authors compared 24-h activity levels between $\mathrm{CHF}$ patients, with or without SDB. In addition, subjective and objective measures of daytime sleepiness were compared.

The current authors hypothesised that $\mathrm{CHF}$ patients with SDB would have decreased levels of daytime activity, compared with $\mathrm{CHF}$ patients with no SDB (NoSDB), which may in turn explain the lack of excessive daytime sleepiness.

\section{AFFILIATIONS}

${ }^{*}$ Clinical and Academic Unit of Sleep and Breathing, National Heart and Lung Institute, Imperial College, and

${ }^{\text {\#C} C a r d i a c ~ M e d i c i n e, ~ a n d ~}$

'Sleep and Ventilation Unit, Royal Brompton Hospital, London, UK.

CORRESPONDENCE

M.J. Morrell

Sleep and Ventilation Unit

2nd floor

Royal Brompton Hospital

Fulham Road

London

SW3 6NP

UK

Fax: 442073518911

E-mail:m.morrell@imperial.ac.uk

Received:

May 312005

Accepted after revision:

December 122005

SUPPORT STATEMENT

This work was supported by the British Heart Foundation, the Wellcome Trust, Medical Expeditions and an educational grant from ResMed UK Ltd. 


\section{METHODS}

\section{Subjects}

A group of 39 consecutive male $\mathrm{CHF}$ patients were recruited from cardiology clinics as part of a wider study assessing the prevalence of SDB in mild-to-moderate heart failure patients [12]. All patients who had taken part in the prevalence study $(n=55)$, were approached and invited to participate in the present study, apart from those who had started to undergo treatment for SDB $(n=8)$. Eight patients declined to take part in the study. Selection was not determined by the presence or absence of daytime sleepiness.

Inclusion criteria involved all patients receiving optimal medical therapy (table 1) and having stable heart failure, defined by no changes in cardiac medication 4 weeks prior to and during the study. Individuals with a forced expiratory volume in one second (FEV1)/forced vital capity (FVC) ratio of $<0.70$ or chronic neurological disease, were excluded. Patients being treated for sleep disorders or with concurrent diseases that were likely to affect the control of breathing for other reasons, i.e. cerebral infarction, chronic neurological disease, or receiving hypnotic/sedative/opiate drug treatment, were also excluded. Patients were divided into two groups: SDB $(n=22)$ and NoSDB $(n=17)$. Systolic function was not significantly

\begin{tabular}{|c|c|c|c|}
\hline & SDB & NoSDB & p-value \\
\hline Patients n & 22 & 17 & \\
\hline \multicolumn{4}{|l|}{ Characteristic } \\
\hline Age yrs & $65.6 \pm 10.5$ & $59.8 \pm 12.5$ & 0.12 \\
\hline $\mathrm{BMI} \mathrm{kg} \cdot \mathrm{m}^{-2}$ & $29.4 \pm 6.2$ & $28.5 \pm 3.5$ & 0.59 \\
\hline LVEF \% & $33.4 \pm 12.4$ & $32.3 \pm 9.5$ & 0.78 \\
\hline Peak $V^{\prime} \mathrm{O}_{2} \mathrm{~mL} \cdot \mathrm{kg}^{-1} \cdot \mathrm{min}^{-2}$ & $15.4 \pm 4.2$ & $17.6 \pm 3.9$ & 0.11 \\
\hline NYHA class & $2.3 \pm 0.5$ & $2.1 \pm 0.2$ & 0.17 \\
\hline $\mathrm{Pa}, \mathrm{CO}_{2} \mathrm{kPa}$ & $4.6(0.4)$ & $4.7(0.5)$ & 0.53 \\
\hline Employment $h \cdot$ week $^{-1}$ & $0(0-50)$ & $0(0-40)$ & 0.15 \\
\hline Nap opportunity ${ }^{\#}$ & $3(1-3)$ & $3(1-3)$ & 0.26 \\
\hline Alcohol units $\cdot$ week $^{-1}$ & $3(0-22)$ & $4(0-43)$ & 0.42 \\
\hline \multicolumn{4}{|l|}{ Diagnosis } \\
\hline Ischaemic dilated cardiomyopathy & $14(64)$ & $7(41)$ & 0.61 \\
\hline Idiopathic dilated cardiomyopathy & $8(36)$ & $10(59)$ & 0.64 \\
\hline \multicolumn{4}{|l|}{ Medication } \\
\hline Beta-blockers & $17(77)$ & $13(76)$ & 0.70 \\
\hline $\begin{array}{l}\text { ACE inhibitor/angiotensin II } \\
\text { receptor antagonist }\end{array}$ & $21(95)$ & $17(100)$ & 0.70 \\
\hline Digoxin & $4(18)$ & $6(35)$ & 0.90 \\
\hline Diuretics & $21(95)$ & $15(88)$ & 0.60 \\
\hline Warfarin & $9(41)$ & $8(47)$ & 0.82 \\
\hline \multicolumn{4}{|l|}{ Comorbidity } \\
\hline Diabetes mellitus & $4(18)$ & $1(6)$ & 0.22 \\
\hline Atrial fibrillation & $7(32)$ & $6(35)$ & 0.65 \\
\hline Arthritis & $1(5)$ & $4(18)$ & 0.33 \\
\hline
\end{tabular}

Data are presented as mean $\pm \mathrm{SD}$, median (range) or $\mathrm{n}(\%)$ unless otherwise stated. SDB: sleep-disordered breathing; NoSDB: no SDB: BMI: body mass index; LVEF: left-ventricular ejection fraction; $V^{\prime} \mathrm{O}_{2}$ : oxygen uptake; NYHA: New York Heart Association; $\mathrm{Pa}_{1} \mathrm{CO}_{2}$ : carbon dioxide arterial tension; ACE: angiotensin converting enzyme. ${ }^{\#}$ : 1 =low opportunity, $3=$ high opportunity. different between the two groups after grouping for SDB status. However, no patients were removed from the analysis on the basis of matching for systolic function, and the matching of the groups occurred by chance.

Sleep staging was scored using the standard methods of RECHSTAFFEN and KALES [13] for 30-s epochs. SDB was measured by polysomnography and defined as an AHI >15 events $\cdot h^{-1}$ [4]. Respiratory events were scored as follows: apnoea, the presence of no airflow for $>10 \mathrm{~s}$; hypopnoea, a $50 \%$ reduction in airflow for $>10 \mathrm{~s}$ in the presence of a $4 \%$ desaturation or an arousal; central sleep apnoea (CSA), $\geqslant 50 \%$ of apnoeas central or mixed; OSA, $>50 \%$ of apnoeas obstructive. The mean \pm SD time between polysomnography and actigraphy was $3 \pm 3.3$ months.

At the time of polysomnography, the patient's height and weight were measured and their body mass index (BMI) calculated (weight $\cdot$ height $^{-2}$ ). A complete two-dimensional and Doppler echocardiography study was performed for each patient. Left-ventricular ejection fraction (LVEF) was assessed by single plane Simpson's method [14]. Patients underwent ergometric cardiopulmonary exercise test (Oxycon; Jaeger Toennies Ltd, Höchberg, Germany) from which peak oxygen uptake $\left(V^{\prime} \mathrm{O}_{2}\right)$ was calculated. Carbon dioxide arterial tension $\left(\mathrm{Pa}_{\mathrm{a}} \mathrm{CO}_{2}\right)$ was measured from blood taken from the ear lobe, prior to polysomnography. All cardiac measurements were taken within $24 \mathrm{~h}$ of the overnight polysomnography.

All participants gave written, informed consent, and the study was approved by the local ethics committee.

\section{Protocol}

The patients wore an Actiwatch ${ }^{\circledR}$ (Model AW4; Cambridge Neurotechnology Ltd, Cambridge, UK) on their nondominant wrist for 2 weeks. Daily sleep diaries were kept to report bed and get-up times, nocturnal urination events and daytime napping. Individual daily data were omitted if the Actiwatch ${ }^{\circledR}$ was removed for $>2 \mathrm{~h}$. The current authors obtained $>13$ days of 24 -h data from 28 of the 39 patients $(72 \%)$ involved; 11 or 12 days' data was compiled in a further seven patients $(18 \%)$ and $10,9,8$ and 7 days' data were collected for each subject, respectively, in the remaining $10 \%$. One subject failed to wear the Actiwatch ${ }^{\circledR}$ during the day on 12 days out of the 14 days studied, and one failed to wear the Actiwatch ${ }^{\circledR}$ throughout the night on all nights, consequently their daytime and nocturnal data, respectively, were removed.

\section{Actigraphy measurement}

The Actiwatch ${ }^{\circledR}$ measures activity with a piezo-electric accelerometer that records intensity, amount and duration of movement in all directions. All movement over $0.05 \mathrm{~g}$ with a maximum sampling frequency of $32 \mathrm{~Hz}$ is recorded. Actigraphical data from 1-min epochs were collated and automatic scoring of sleep was performed using a validated algorithm [15]. This algorithm modifies recorded activity counts in one epoch (1 $\mathrm{min})$ according to the level of activity in the surrounding $2 \mathrm{~min}( \pm 2 \mathrm{~min})$ to give a final activity count for each epoch. The total value is used to decide if the epoch is scored as wake or sleep. During the current analysis, a threshold of $>40$ counts $\cdot$ epoch $^{-1}$ was used to define wake. 


\section{Nocturnal activity analysis}

For the nocturnal period, bed and get-up times were set according to cues (actigraph event marker or sleep diary entry). If the times recorded using the actigraphy event marker differed from the sleep diary then the actigraphy event marker was considered more reliable compared with the patient's estimations entered in the sleep diary. The onset and end of sleep were also manually estimated using actigraphy from the first and last periods of quiescence, respectively; however, this may or may not have reflected sleep and wake times that would have been defined had the changes in the frequency of the electroencephalogram been measured. Time in bed (TIB), sleep latency (SL), sleep efficiency (SE), movement time and fragmentation index (calculated as the percentage of the number of phases of immobility of $\leqslant 1 \mathrm{~min}$ against the total number of immobility phases; immobility phase: $>1$ consecutive epochs with a score of zero) were all calculated by the actigraphy sleep-wake algorithm.

\section{Daytime activity analysis}

The daytime period was analysed using actigraphy software following manual prompts. Activity was taken to be any movement associated with wakefulness; the actiwatch did not discriminate between arm movement activities and whole body exercise. The duration of daytime activity was defined as the time between the first period of activity following sleep and the last period of activity preceding sleep. Activity counts per epoch during the day were added to produce the total daytime-activity count per day.

\section{Nap analysis}

Naps were objectively analysed using the actigraphy analysis software and subjectively analysed using cues from patients' individual sleep diaries. The minimum nap period was set at $10 \mathrm{~min}$. The algorithm for nap analysis classified an epoch as sleep if the activity counts in an epoch fell below a certain threshold; this was set at zero. For each daytime period an objective and subjective mean nap time was calculated.

\section{Subjective and objective sleepiness assessment}

An objective SL test (Oxford Sleep Resistance test (OSLER); Stowood Scientific Instruments, Oxford, UK) was carried out [16]. In the majority of patients this was done at the time of the actigraphy study $(n=27)$; in the remaining patients $(n=12)$ this was assessed within 8 weeks (median 6 , range 1-8 weeks). The OSLER test was undertaken between 13:30 h and 19:30 h (median was 16:30 h) in a darkened, quiet room. The patients had not eaten or had any caffeinated drinks within $1 \mathrm{~h}$ prior to the test. The patients were asked to maintain wakefulness for the maximum testing time of $40 \mathrm{~min}$. Sleep was considered to have occurred when seven consecutive cues were missed, which corresponded to a time of $21 \mathrm{~s}$. An Epworth Sleepiness Scale (ESS) questionnaire [17] was completed prior to the start of actigraphy.

\section{Statistical analysis}

All data were tested for normality. Unpaired t-tests or MannWhitney rank-sum tests were used to compare groups for variables and group characteristics. Z-tests were used to compare proportions. ANOVA was used to compare the time of day that the OSLER test was taken for all subjects. Results are expressed as mean $\pm \mathrm{SD}$ or median (range). Statistical significance was accepted as $\mathrm{p} \leqslant 0.05$.

\section{RESULTS}

\section{Subject characteristics}

A total of 39 patients were studied. There were no significant differences in age, BMI, LVEF, peak $V^{\prime} \mathrm{O}_{2}$, New York heart Association, $\mathrm{Pa}_{1} \mathrm{CO}_{2}$, hours of employment, nap opportunity or alcohol consumption between CHF patients with and without SDB. Group characteristics are shown in table 1.

\section{Polysomnography data}

The SDB group had a median (range) AHI of 22.3 (16.6-100) and the NoSDB group $3.7(0-12.3)$ events $\cdot h^{-1}(p<0.001)$. Of the SDB group, 12 patients had CSA and 10 patients had OSA. The SDB and NoSDB groups differed significantly in desaturation index $(p<0.01)$, SE $(p=0.01)$ and arousal index $(p<0.001)$. CHF patients with SDB tended to have more stage 1 sleep, although this did not reach statistical significance. Both groups had similar amounts of deep and rapid eye movement sleep. Polysomnography data are shown in table 2.

\section{4-h activity from the actigraph}

The 24-h activity data, over 2 weeks, in one CHF patient with $\mathrm{SDB}$ and one without SDB are shown in figure 1. Comparisons

\begin{tabular}{|c|c|c|c|}
\hline & SDB & NoSDB & p-value \\
\hline Patients n & 22 & 17 & \\
\hline \multicolumn{4}{|l|}{ Characteristic } \\
\hline $\mathrm{AHI}$ events $\cdot \mathrm{h}^{-1}$ & $22.3(16.6-100)$ & $3.7(0-12.3)$ & $<0.001$ \\
\hline $\begin{array}{l}\text { Obstructive Index } \\
\text { events } \cdot \mathrm{h}^{-1}\end{array}$ & $6.4(0.2-93.2)$ & $0.8(0.0-7.7)$ & $<0.001$ \\
\hline Central Index events $\cdot \mathrm{h}^{-1}$ & $3.4(0.0-16.5)$ & $0.2(0.0-6.2)$ & $<0.01$ \\
\hline Mixed Index events $\cdot h^{-1}$ & $0.6(0.0-9.4)$ & $0.0(0.0-1.3)$ & $<0.001$ \\
\hline $\begin{array}{l}\text { Hypopnoea Index } \\
\text { events } \cdot h^{-1}\end{array}$ & $11.8(0.0-29.6)$ & $1.6(0.0-8.7)$ & $<0.001$ \\
\hline $\begin{array}{l}\text { Desaturation Index events } \\
\left.\quad>4 \% \cdot h^{-1}\right)\end{array}$ & $6.5(0.0-45.0)$ & $1.0(0.0-17.0)$ & $<0.01$ \\
\hline Minimum $\mathrm{O}_{2}$ value ${ }^{\#}$ & $85(47-92)$ & $89(47-96)$ & 0.02 \\
\hline Total sleep time $\mathrm{h}$ & $5.1 \pm 1.1$ & $5.5 \pm 1.3$ & 0.24 \\
\hline SL min & $17 \pm 6-88$ & $11 \pm 1-38$ & 0.03 \\
\hline SE TIB asleep \% & $62.6 \pm 10.9$ & $72.2 \pm 12.2$ & 0.01 \\
\hline Arousal Index events $\cdot \mathrm{h}^{-1}$ & $40.7(13.9-117.9)$ & $19.4(5.3-49.8)$ & $<0.001$ \\
\hline \multicolumn{4}{|l|}{ Stage of sleep $\%$} \\
\hline 1 & $39 \pm 16$ & $30 \pm 14$ & 0.07 \\
\hline 2 & $34 \pm 12$ & $40 \pm 11$ & 0.10 \\
\hline 3 and 4 & $11 \pm 7$ & $11 \pm 7$ & 0.86 \\
\hline REM & $16 \pm 8$ & $18 \pm 8$ & 0.46 \\
\hline \multicolumn{4}{|c|}{$\begin{array}{l}\text { Data presented as mean } \pm \text { SD and median (range), unless otherwise stated. } \\
\text { SDB: sleep-disordered breathing; NoSDB: no SDB; AHI: apnoea/hypopnoea } \\
\text { index; SL: sleep latency; SE: sleep efficiency; TIB: time in bed; REM: rapid eye } \\
\text { movement. }{ }^{\#} \text { : note that the minimum oxygen desaturation value was } 47 \% \text { in } \\
\text { both groups. This was due to isolated obstructive apnoeas with significant } \\
\text { desaturation in one NoSDB patient. Congestive heart failure patients with SDB } \\
\text { regularly desaturated to low levels. }\end{array}$} \\
\hline
\end{tabular}


of each group's mean nocturnal parameters are given in table 3. CHF patients with SDB spent a significantly longer TIB $(p=0.01)$ compared with the NoSDB group. However, their sleep was more disturbed, as shown by the significantly increased movement time $(\mathrm{p}=0.006)$ and fragmentation index $(p=0.003)$. SE tended to be worse in the SDB group, although this did not reach statistical significance $(p=0.06)$. SL did not differ significantly between the two groups $(p=0.17)$.

Daytime activity levels in one CHF patient with SDB and one without SDB are shown in figure 2. The individual and group mean daytime activity are shown in figure 3. For the SDB group the daytime activity duration was significantly shorter than that of the NoSDB group $(p=0.004)$. Within this period the CHF patients with SDB tended to be less active, although this did not reach statistical significance (total activity counts $\mathrm{p}=0.06$; average activity/epoch $\mathrm{p}=0.08$; table 3 ).

The current authors correlated 24-h activity parameters with SDB severity on the basis of AHI. As a continuous variable, AHI weakly correlated with daytime activity duration $\left(\mathrm{r}^{2}=0.15, \mathrm{p}=0.02\right)$. There were no further significant correlations between the parameters of $P a, C_{2}$, LVEF and peak $V^{\prime} \mathrm{O}_{2}$ which the current authors used to define cardiac status and the actigraphy measurements of TIB, SE, fragmentation index and daytime activity duration ( $p>0.05$ ). These cardiac parameters also showed no correlation with AHI, ESS or OSLER test results $(\mathrm{p}>0.05)$.

There were no significant differences $(p>0.05)$ in actigraphy results (TIB, SE, fragmentation index, daytime activity duration or total daytime activity counts) for those patients who

\begin{tabular}{|c|c|c|c|}
\hline & SDB & NoSDB & p-value \\
\hline Patients n & 21 & 17 & \\
\hline \multicolumn{4}{|l|}{ Parameter } \\
\hline Actigraphy TIB h & $8.53 \pm 1.11$ & $7.65 \pm 0.86$ & 0.01 \\
\hline Actigraphy SL min & $22 \pm 19$ & $15 \pm 8$ & 0.17 \\
\hline Actigraphy SE, TIB asleep \% & $74.9 \pm 10.5$ & $80.5 \pm 6.0$ & 0.06 \\
\hline $\begin{array}{l}\text { Actigraphy sleep movement } \\
\text { time, TIB moving } \%\end{array}$ & $25.3 \pm 10.9$ & $16.9 \pm 5.0$ & $<0.01$ \\
\hline Actigraphy fragmentation index & $53.2 \pm 19.6$ & $36.3 \pm 10.0$ & $<0.01$ \\
\hline Daytime activity duration $\mathrm{h}$ & $15.2 \pm 1.2$ & $16.3 \pm 1.0$ & $<0.01$ \\
\hline $\begin{array}{l}\text { Total daytime activity counts } \\
\qquad \times 10^{4}\end{array}$ & $2.3 \pm 8.1$ & $2.9 \pm 9.7$ & 0.06 \\
\hline $\begin{array}{l}\text { Average daytime activity counts. } \\
\text { epoch }^{-1}\end{array}$ & $251 \pm 82$ & $305 \pm 100$ & 0.08 \\
\hline
\end{tabular}

Data are presented as mean \pm SD. SDB: sleep-disordered breathing; NoSDB: no SDB; TIB: time in bed; SL: sleep latency; SE: sleep efficiency.

had actigraphy at the time of polysomnography (SDB, $n=10$; NoSDB, $n=6)$ and for those who had measurements at $>1$ month apart (SDB, $\mathrm{n}=12$; NoSDB, $\mathrm{n}=11)$.

\section{Subjective and objective daytime sleepiness}

There was no significant difference between the SDB and NoSDB groups for subjective ESS (median (range); SDB: 7 (216); NoSDB: $9(2-17) ; p=0.55)$, yet objectively the SDB group

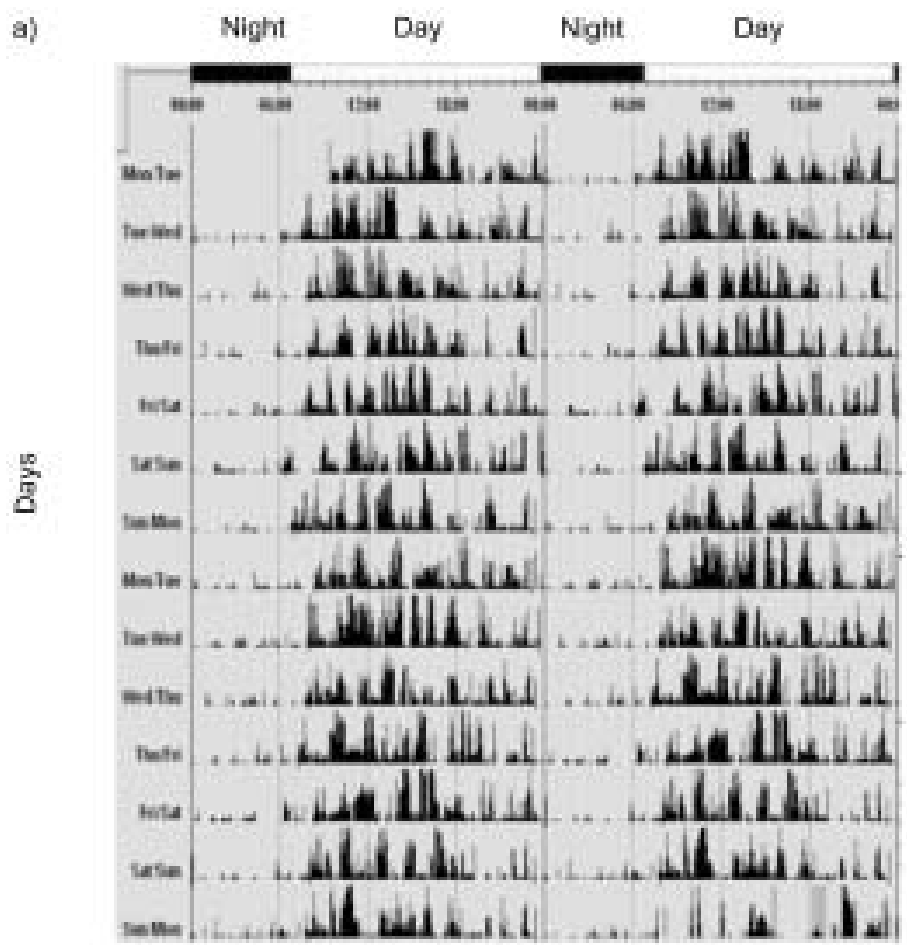

b)

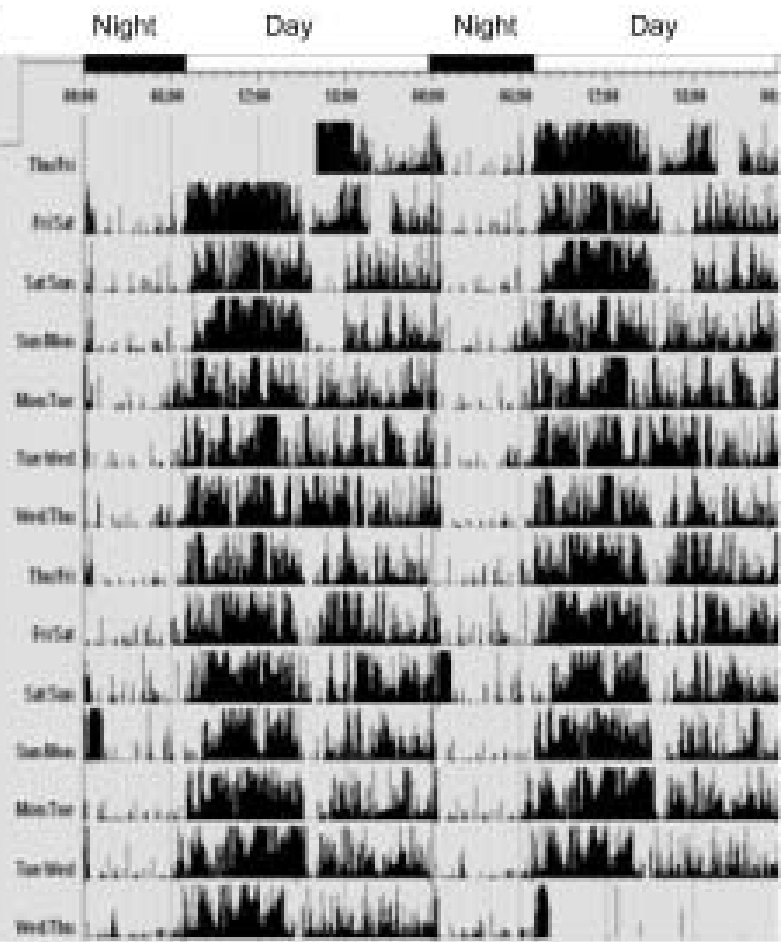

FIGURE 1. Representative actigrams are $>2$ weeks (dual-day display) from congestive heart failure (CHF) patients with a) sleep-disordered breathing (SDB) and b) no SDB. Patients without SDB have a significantly more active daytime profile. Sleep fragmentation is similar in the two patients presented in this figure, despite being significantly increased in the group's mean for CHF patients with SDB. Notice that peaks of activity during the night are associated with nocturnal urination events. 

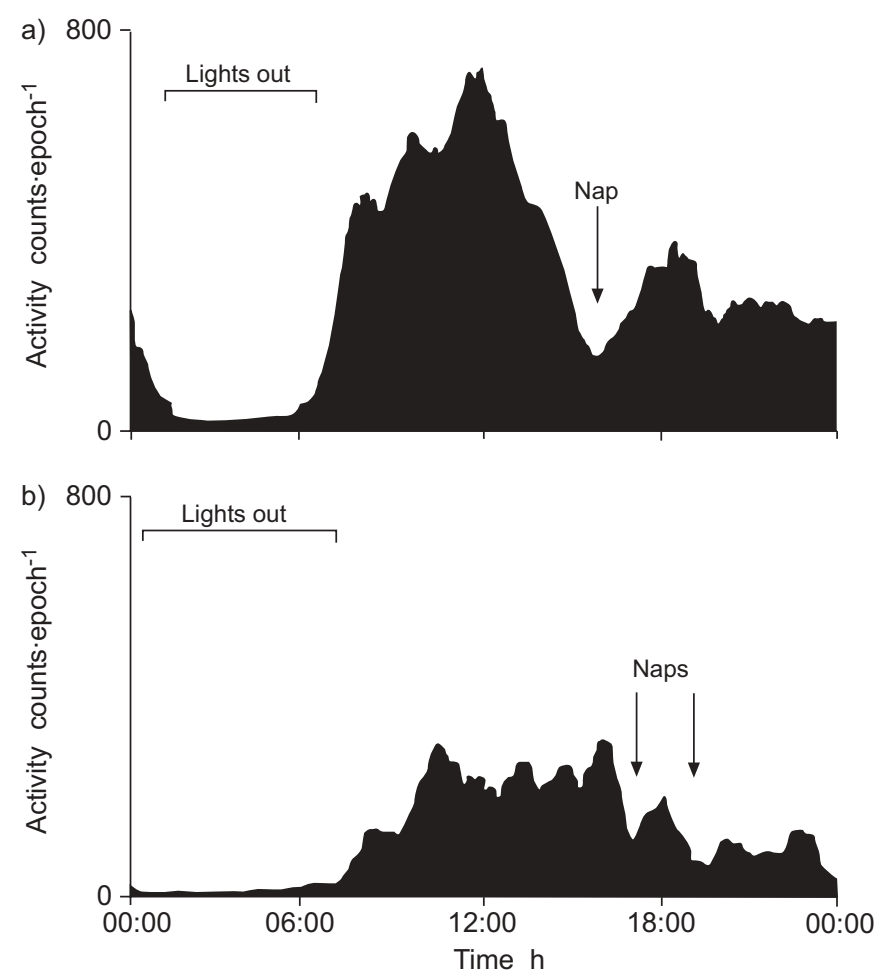

FIGURE 2. Examples of average 24-h activity levels for a congestive heart failure (CHF) patient a) with no sleep-disordered breathing NoSDB and b) with SDB. These data highlight the longer time in bed and reduced activity in CHF patients with SDB. The traces also show daily nap times. Nap times are as reported in daily sleep diaries. The levels of activity do not reach the low levels seen during sleep as the plot is an average over a 2-week period, during which not all naps are at the same time or duration. Both patients had similar levels of sleep fragmentation; however, the intensity of movement (total activity counts) during sleep was greater in the CHF patient without SDB. This produced higher activity levels during the lights-out period.

were significantly sleepier on the OSLER test (SDB: 17.1 (3-40) min; NoSDB: 40.0 (12-40) $\mathrm{min} ; \mathrm{p}=0.01)$.

OSLER results were further separated according to the time of day the test was taken (13:30-15:30, 15:31-17:30 and 17:3119:30 h). The current authors found no significant differences in the SL recorded by the OSLER test for each time of day $(p=0.77)$.

\section{Behavioural symptoms}

The mean subjective total nap time per day was similar in the SDB and NoSDB groups; although there was a wide range of variability within each group (mean \pm SD; SDB: $22.9 \pm 17.9$ min'day ${ }^{-1}$; NoSDB: $\left.26.1 \pm 23.0 \mathrm{~min} \cdot \mathrm{day}^{-1} ; \mathrm{p}=0.69\right)$. Daytime napping was also analysed objectively from actigraphy; individual examples of naps are seen in figure 2 . The mean objective nap time was similar for the SDB and NoSDB groups (SDB: $\left.26.1 \pm 27.2 \mathrm{~min} \cdot \mathrm{day}^{-1}, \mathrm{NoSDB}: 19.6 \pm 18.6 \mathrm{~min} \cdot \mathrm{day}^{-1}, \mathrm{p}=0.36\right)$. There was no significant difference between the groups in the percentage of days when naps were taken (SDB: $64 \pm 48 \%$ days, NoSDB: $49 \pm 30 \%$ days; $\mathrm{p}=0.26$ ).

Nocturnal urination was reported at a higher frequency in the SDB group than the NoSDB group, although this did not reach

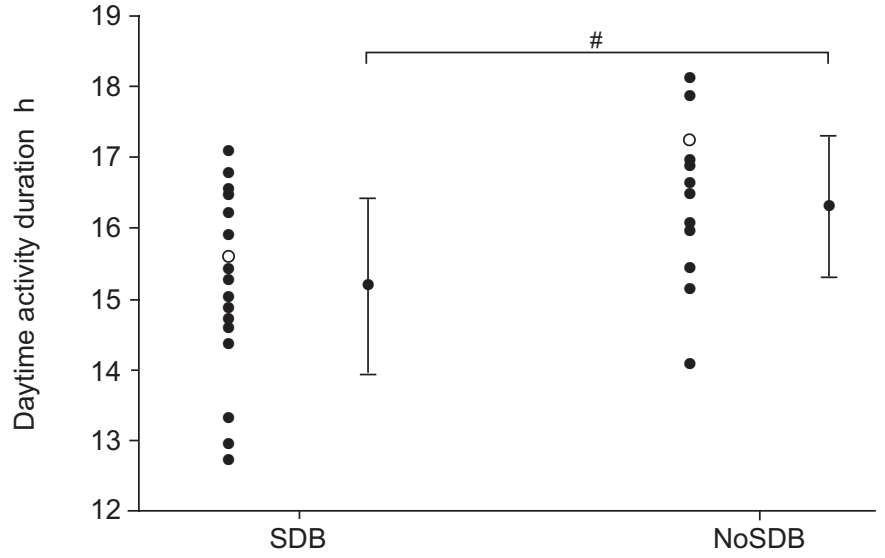

FIGURE 3. Length of daytime activity duration between get-up and bedtime for the two groups. Results show individual durations in hours, with mean $\pm S D$. $O$ : patients represented in figures 1 and 2. SDB: Sleep-disordered breathing; NoSDB: no SDB. ${ }^{*}: p=0.004$.

statistical significance (SDB: $1.7 \pm 1.2$ times $\cdot$ night $^{-1}$, NoSDB: $1.0 \pm 0.9$ times night $\left.^{-1}, \mathrm{p}=0.07\right)$.

\section{DISCUSSION}

This is the first study to monitor 24-h activity levels in CHF patients with and without SDB. The main findings were that CHF patients with SDB spent longer periods of time in bed, they had more fragmented sleep and tended to be less active during the day than a group of CHF patients without SDB, who had no significant differences in cardiac parameters, age or BMI. Consistent with previous studies, the current results show that CHF patients with SDB report very little daytime sleepiness, yet objectively there was a significant difference in daytime sleepiness. These data highlight the fact that $\mathrm{CHF}$ patients with SDB underestimate their daytime sleepiness symptoms. The current authors speculate that the reduced perception of sleepiness may, in part, be due to reduced levels of daytime activity with longer periods in bed.

The use of 24-h actigraphy, over a 2-week period, in the current study, allowed the authors to obtain accurate data on sleeping habits which cannot be determined during single, overnight polysomnography in a sleep laboratory. The increased sleep fragmentation on the actigraphy traces in the SDB group suggests that these patients are having disturbed sleep when at home. These data are consistent with the decreased SE and increased number of arousals scored in the polysomnography. Sleep fragmentation indices, from a number of different techniques, have been shown to be useful in identifying OSA patients with sleepiness, who are likely to respond to CPAP treatment [18]. Thus, this could be a useful parameter in assessing which CHF patients with SDB would benefit from treatment.

The current authors found that subjective and objective measurements of sleepiness in CHF patients with SDB, produced different results. CHF patients with SDB are objectively, but not subjectively, sleepy during the day. This result has been seen in previous studies $[6,19]$. The ESS is widely and easily used in the clinical setting; however, the 
difference between subjective and objective sleepiness results within the CHF with SDB group could be accounted for as the ESS produces highly variable results $[19,20]$. The ESS may not always be applicable to older heart failure patients who no longer drive and have plenty of opportunity for daytime napping.

It has been speculated that the lack of differences in subjective sleepiness are due to overlapping symptoms of heart failure, including medications, with symptoms of SDB [4]. An alternative explanation is that despite sleep fragmentation, CHF with SDB patients are able to maintain relatively normal levels of deep sleep. In the current study the percentage of deep sleep $(11 \%)$ was comparable to that found in the Wisconsin Sleep Cohort study $(n=352$; average being 9\%); however, these data were collected in people who were younger (aged 30-60 yrs) than the current study population [21]. It is known that increasing age decreases the amount of deep sleep [22], although reports differ as to the magnitude of the decrease. In one report, deep sleep in healthy males decreased from $19 \%$ in $16-25$ yr olds, to $3 \%$ in $36-50$ yr olds; with no further significant decreases in old age (71-83 yrs) [23]. Alternatively, in the Sleep Heart Health Study $(n=2,685)$ deep sleep decreased from $11 \%$ in $<54 \mathrm{yr}$ olds, to $7 \%$ in $61-71 \mathrm{yr}$ olds [24]. Decreases in deep sleep can also occur in patients with respiratory disturbances, who are otherwise healthy [24]. In patients with $\mathrm{CHF}$ and SDB, some $[6,25]$ but not all $[4,5,26]$ studies have reported percentages of deep sleep that are comparable to those found in the present study.

The current authors investigated the levels of daytime napping in $\mathrm{CHF}$ patients. Both groups reported similar amounts of napping and these values closely matched the objective values recorded by actigraphy. This good reliability of nap reporting has not always been shown in actigraphy studies [27]. In the recent study by YoON et al. [8], older adults (mean age $66.2 \pm 4.9 \mathrm{yrs}$ ) were studied with actigraphy. Objectively they napped for $23.3 \mathrm{~min} \cdot \mathrm{day}^{-1}$, which correlates well with subjective and objective data in the current CHF patients. However, an earlier study reported that healthy, elderly subjects napped for $59.8 \mathrm{~min} \cdot \mathrm{day}^{-1}$ on average [28], which is significantly greater than either of the current patient groups. It is therefore difficult to say conclusively whether the levels of napping found in the present study are similar to a healthy, elderly population. There have been suggestions that nocturnal activity changes with increasing age [27] and that actigraphy algorithms are not necessarily equally accurate for adults at differing ages [29]. However, since the current groups studied, with or without SDB, showed no significant differences in age and disease severity this contention is unlikely to have influenced the results obtained from the current study.

The present authors separated the data into two groups due to the symptoms of SDB being more common in CHF patients at an AHI of $>15$ events $\cdot h^{-1}$ [4], despite some studies using an AHI $>10$ to define mild sleep apnoea $[5,30]$. An AHI of 15 is the value used by JAVAHERI et al. [4] in the benchmark prevalence study of $81 \mathrm{CHF}$ patients to define SDB. Separation of the current data, using the same cut-off, allowed the current results to be compared with those of this seminal paper.

\section{Limitations}

A potential limitation of the current study was the variation in the time taken between polysomnography and actigraphy $(3 \pm 3.3$ months). Due to the unstable nature of $\mathrm{CHF}$ this may have led to small changes in cardiac parameters prior to actigraphy measurements. However, there were no changes in medication, any hospitalisations or decompensations during this time. Also, the number of patients in the SDB and NoSDB groups, who had polysomnography $>1$ month, apart from the actigraphy and OSLER test, was equal in both groups and there were no significant differences in all results between these sets of patients.

Due to the large amount of overlap between the current groups in activity levels, the present study would have been improved with a group of healthy elderly controls. The inclusion of healthy elderly controls could have highlighted that CHF alone reduces activity [31]. However, from previous studies it is known that healthy elderly people (without $\mathrm{CHF}$ ) have increased levels of daytime napping compared with healthy young controls [32], which may indicate that reduced daytime activity is a function of age rather than CHF. In this scenario there would continue to be a large amount of crossover between age-matched groups of $\mathrm{CHF}$ patients with and without SDB, but any small differences would highlight the impact of SDB on daytime activity levels.

The current authors used a single OSLER test. MAZZA et al. [33] reported that a single 09:00 h OSLER test was as sensitive as three consecutive tests in identifying patients with significant daytime sleepiness. In the present study, patients were tested between 13:30 and 19:30 h (median: 16:30 h). This may have reduced the patient's ability to perform the test, due to their afternoon peak in physiological somnolence [33]. However, the OSLER results were significantly different between $\mathrm{CHF}$ patients with and without SDB in terms of SL. The absolute values were similar to those of PEPPERELL et al. [6], who showed an improvement in objective daytime sleepiness, measured using four OSLER tests during 1 day, in a group of $\mathrm{CHF}$ patients with SDB, who were treated with adaptive servo controlled ventilation for a 1-month period. Furthermore, the current authors found no significant difference in the SL results of the OLSER test between those patients who had the test at different times during the afternoon.

The number of patients recruited was lower than the desired number calculated from a prospective power calculation. From the study by ROSENTHAL et al. [34], significant differences in daytime napping duration were found between severe $\left(37.3 \pm 47.5 \mathrm{~min} \cdot \mathrm{day}^{-1}\right)$ and $\mathrm{mild}\left(24.4 \pm 30.6 \mathrm{~min} \cdot \mathrm{day}^{-1}\right)$ OSA patients. Using these differences, with a power of $80 \%$ and significance of 0.05 , it was calculated that 90 patients would be needed in each group. Such high numbers of CHF patients with and without SDB were unavailable to the current authors over the study period selected; therefore, the maximum number of patients that agreed to partake in the current study were selected (see methods). There was no previous data available to perform a power calculation on activity levels. A retrospective power calculation ( $80 \%$ power; 0.05 significance) of the current daytime-activity duration data shows that groups of 13 would have produced significant results. 
However, 131 patients per group would have been required to find a significant difference in objective daytime napping.

\section{Clinical implications}

$\mathrm{SDB}$ in $\mathrm{CHF}$ is common and associated with sleep disruption, oxyhaemoglobin desaturation [4] and a poor prognosis [35, 36]. It is therefore important to understand the full symptom profile of SDB in CHF patients in order to develop effective treatment regimes. Treatment of SDB in CHF patients with oxygen, CPAP, and adaptive servo-ventilation have reduced apnoeas by as much as $80 \%[25,37]$, and 1 month of adaptive sero-ventilation has been shown to reduce objective daytime sleepiness, and produce a fall in brain natriuretic peptide and urinary metadrenaline excretion [6].

Patients with CHF have shown improved outcomes following exercise programmes [38]. With further reduced activity levels in patients with SDB there may be further detrimental effects on the heart. Treatment of SDB may allow increased activity and an increased chance of cardiac improvement on an exercise programme.

Despite the lack of symptoms of daytime sleepiness, congestive heart failure patients with sleep-disordered breathing are objectively sleepier during the day, spend longer in bed, have more fragmented sleep and tend to have reduced daytime activity. This suggests that these patients may benefit from treatment. If treatment is to be evaluated effectively, subjective measures of sleepiness may not show significant improvements. However, actigraphy and the Oxford Sleep Resistance test may be useful in assessing improvements in sleep fragmentation, the length of time spent in bed and the objective sleepiness in these patients, and in assessing which patients may greater benefit from treatment.

\section{ACKNOWLEDGEMENTS}

The authors would like to thank M.R. Cowie, P.A. PooleWilson and H.F. McIntyre for allowing the recruitment of patients from their cardiology departments (National Heart and Lung Institute, Imperial College London and Royal Brompton Hospital, London, and The Conquest Hospital, Hastings, UK).

\section{REFERENCES}

1 George CF. Reduction in motor vehicle collisions following treatment of sleep apnoea with nasal CPAP. Thorax 2001; 56: 508-512.

2 Hardinge FM, Pitson DJ, Stradling JR. Use of the Epworth Sleepiness Scale to demonstrate response to treatment with nasal continuous positive airways pressure in patients with obstructive sleep apnoea. Respir Med 1995; 89: 617-620.

3 Montserrat JM, Ferrer M, Hernandez L, et al. Effectiveness of CPAP treatment in daytime function in sleep apnea syndrome: a randomized controlled study with an optimized placebo. Am J Respir Crit Care Med 2001; 164: 608-613.

4 Javaheri S, Parker TJ, Liming JD, et al. Sleep apnea in 81 ambulatory male patients with stable heart failure. Types and their prevalences, consequences, and presentations. Circulation 1998; 97: 2154-2159.
5 Sin DD, Fitzgerald F, Parker JD, Newton G, Floras JS, Bradley TD. Risk factors for central and obstructive sleep apnea in 450 men and women with congestive heart failure. Am J Respir Crit Care Med 1999; 160: 1101-1106.

6 Pepperell JC, Maskell NA, Jones DR, et al. A randomized controlled trial of adaptive ventilation for Cheyne-Stokes breathing in heart failure. Am J Respir Crit Care Med 2003; 168: 1109-1114.

7 Kushida CA, Chang A, Gadkary C, Guilleminault C, Carrillo O, Dement WC. Comparison of actigraphic, polysomnographic, and subjective assessment of sleep parameters in sleep-disordered patients. Sleep Med 2001; 2: 389-396.

8 Yoon IY, Kripke DF, Youngstedt SD, Elliott JA. Actigraphy suggests age-related differences in napping and nocturnal sleep. J Sleep Res 2003; 12: 87-93.

9 Sadeh A, Hauri PJ, Kripke DF, Lavie P. The role of actigraphy in the evaluation of sleep disorders. Sleep 1995; 18: 288-302.

10 Sadeh A, Acebo C. The role of actigraphy in sleep medicine. Sleep Med Rev 2002; 6: 113-124.

11 Blood ML, Sack RL, Percy DC, Pen JC. A comparison of sleep detection by wrist actigraphy, behavioral response, and polysomnography. Sleep 1997; 20: 388-395.

12 Vazir A, Dayer M, Henein M, et al. Mild congestive heart failure: prevalence and characteristics of sleep disordered breathing. Abstract at the American Thoracic Society annual conference 2004: A465.

13 Rechstaffen A, Kales A. A Manual of Standardized Terminology, Techniques and Scoring System for Sleep Stages of Human Subjects. Washington, Government Printing Office, 1968.

14 Schiller NB, Shah PM, Crawford M, et al. Recommendations for quantitation of the left ventricle by twodimensional echocardiography. American Society of Echocardiography Committee on Standards, Subcommittee on Quantitation of Two-Dimensional Echocardiograms. J Am Soc Echocardiogr 1989; 2: 358-367.

15 Oakley NR. Validation with polysomnography of the sleep-watch sleep/wake scoring algorithm used by the actiwatch activity monitoring system. Technical report to Mini Mitter Co., Inc., 1997.

16 Bennett LS, Stradling JR, Davies RJ. A behavioural test to assess daytime sleepiness in obstructive sleep apnoea. $J$ Sleep Res 1997; 6: 142-145.

17 Johns MW. A new method for measuring daytime sleepiness: the Epworth sleepiness scale. Sleep 1991; 14: 540-545.

18 Bennett, Lesley S, Beverly A, et al. Sleep fragmentation indices as predictors of daytime sleepiness and nCPAP response in obstructive sleep apnea. Am J Respir Crit Care Med 1998; 158: 778-786.

19 Chervin RD, Aldrich MS. The Epworth Sleepiness Scale may not reflect objective measures of sleepiness or sleep apnea. Neurology 1999; 52: 125-131.

20 Sangal RB, Sangal JM, Belisle C. Subjective and objective indices of sleepiness (ESS and MWT) are not equally useful in patients with sleep apnea. Clin Electroencephalogr 1999; 30: 73-75. 
21 Young T, Palta M, Dempsey J, Skatrud J, Weber S, Badr S. The occurrence of sleep-disordered breathing among middle-aged adults. N Engl J Med 1993; 328: 1230-1235.

22 Feinberg I, Koresko RL, Heller N. EEG sleep patterns as a function of normal and pathological aging in man. $J$ Psychiatr Res 1967; 5: 107-144.

23 Van Cauter E, Leproult R, Plat L. Age-related changes in slow wave sleep and REM sleep and relationship with growth hormone and cortisol levels in healthy men. Jama 2000; 284: 861-868.

24 Redline S, Kirchner HL, Quan SF, Gottlieb DJ, Kapur V, Newman A. The effects of age, sex, ethnicity, and sleepdisordered breathing on sleep architecture. Arch Intern Med 2004; 164: 406-418.

25 Teschler H, Dohring J, Wang YM, Berthon-Jones M. Adaptive pressure support servo-ventilation: a novel treatment for Cheyne-Stokes respiration in heart failure. Am J Respir Crit Care Med 2001; 164: 614-619.

26 Tremel F, Pepin JL, Veale D, et al. High prevalence and persistence of sleep apnoea in patients referred for acute left ventricular failure and medically treated over 2 months. Eur Heart J 1999; 20: 1201-1209.

27 Jean-Louis G, Kripke DF, Ancoli-Israel S, Klauber MR, Sepulveda RS. Sleep duration, illumination, and activity patterns in a population sample: effects of gender and ethnicity. Biol Psychiatry 2000; 47: 921-927.

28 Evans BD, Rogers AE. 24-hour sleep/wake patterns in healthy elderly persons. Appl Nurs Res 1994; 7: 75-83.

29 Jean-Louis G, Kripke DF, Cole RJ, Assmus JD, Langer RD. Sleep detection with an accelerometer actigraph: comparisons with polysomnography. Physiol Behav 2001; 72: 21-28.
30 Lanfranchi PA, Braghiroli A, Bosimini E, et al. Prognostic value of nocturnal Cheyne-Stokes respiration in chronic heart failure. Circulation 1999; 99: 1435-1440.

31 Toth MJ, Gottlieb SS, Goran MI, Fisher ML, Poehlman ET. Daily energy expenditure in free-living heart failure patients. Am J Physiol Endocrinol Metab 1997; 272: E469-475.

32 Buysse DJ, Browman KE, Monk TH, Reynolds CF 3rd, Fasiczka AL, Kupfer DJ. Napping and 24-hour sleep/wake patterns in healthy elderly and young adults. J Am Geriatr Soc 1992; 40: 779-786.

33 Mazza S, Pepin JL, Deschaux C, Naegele B, Levy P. Analysis of error profiles occurring during the OSLER test: a sensitive mean of detecting fluctuations in vigilance in patients with obstructive sleep apnea syndrome. Am J Respir Crit Care Med 2002; 166: 474-478.

34 Rosenthal L, Bishop C, Guido P, et al. The sleep/wake habits of patients diagnosed as having obstructive sleep apnea. Chest 1997; 111: 1494-1499.

35 Javaheri S. Central sleep apnea-hypopnea syndrome in heart failure: prevalence, impact, and treatment. Sleep 1996; 19, Suppl. 10, S229-S231.

36 Naughton MT. Is Cheyne-Stokes respiration detrimental in patients with heart failure? Sleep Breath 2000; 4: 127-128.

37 Naughton MT, Liu PP, Bernard DC, Goldstein RS, BradleyTD. Treatment of congestive heart failure and Cheyne-Stokes respiration during sleep by continuous positive airway pressure. Am J Respir Crit Care Med 1995; 151: 92-97.

38 Coats AJ, Adamopoulos S, Radaelli A, et al. Controlled trial of physical training in chronic heart failure. Exercise performance, hemodynamics, ventilation, and autonomic function. Circulation 1992; 85: 2119-2131. 